\title{
Air temperature and inflammatory and coagulation responses in men with coronary or pulmonary disease during the winter season
}

\author{
Regina Hampel, ${ }^{1}$ Susanne Breitner, ${ }^{1}$ Regina Rückerl, ${ }^{1}$ Mark W Frampton, ${ }^{2}$ \\ Wolfgang Koenig, ${ }^{3}$ Richard P Phipps, ${ }^{4}$ H Erich Wichmann, ${ }^{1,5}$ Annette Peters, ${ }^{1}$ \\ Alexandra Schneider ${ }^{1}$
}

- A supplementary figure and table are published online only To view these files please visit the journal online (http://oem. bmj.com).

For numbered affiliations see end of article.

\section{Correspondence to} Regina Hampel, Helmholtz Zentrum München, German Research Center for Environmental Health, Institute of Epidemiology, Ingolstädter Landstr. 1, 85764 Neuherberg, Germany; regina.hampel@ helmholtz-muenchen.de

This article has not been subjected to the U.S. Environmental Protection Agency's required peer and policy review and therefore does not necessarily reflect the views of the Agency and no official endorsement should be inferred.

The Focus Network

Nanoparticles and Health (NanoHealth) coordinates and focuses all Helmholtz Zentrum München research on health effects and the characterisation of aerosols. It comprises research projects in the Institutes of Ecological Chemistry, Epidemiology, Inhalation Biology, Radiation Protection, and Toxicology at Helmholtz Zentrum München.

Accepted 19 October 2009

\section{ABSTRACT}

Background and Objective Air temperature changes are associated with increased cardiovascular and respiratory risk, but the roles of inflammatory and coagulation markers are not well understood. We investigated the associations between temperature and several blood markers in patients with coronary heart disease (CHD) and pulmonary disease (PD).

Methods Two studies were conducted in Erfurt, Germany, over two successive winters. 578 and 381 repeated blood measurements were collected from 57 CHD and 38 PD patients, respectively. Data on patient characteristics and disease history were gathered at baseline. Meteorological data were collected from existing networks. Associations were analysed using additive mixed models with random patient effects. Effect modification by diabetes status was investigated only in CHD patients, as only two PD patients had diabetes.

Results Mean daily air temperature varied between $-13^{\circ} \mathrm{C}$ and $16^{\circ} \mathrm{C}$ in both study periods. $\mathrm{A} 10^{\circ} \mathrm{C}$ decrease in the 5-day temperature average before blood withdrawal led to an increase in platelet counts $1 \%$ change from the mean: $3.0 \%, 95 \% \mathrm{Cl} 0.6 \%$ to $5.5 \%$ ) and fibrinogen $(5.5 \%, 1.3 \%$ to $9.7 \%)$, no change in C-reactive protein in $\mathrm{PD}$ patients, and a decrease in C-reactive protein in CHD patients. A 2-day delayed increase in factor VII associated with temperature decrease was seen in CHD patients (4.9\%; $0.7 \%$ to $9.2 \%$ ), while PD patients showed no effect. 'Effects in CHD patients without diabetes' into 'Effects on factor VII in CHD patients without diabetes'.

Conclusions This study suggests that temperature decrease is associated with change in several blood parameters. The complex interplay of blood markers at low temperature may contribute to the observed association between cold and cardiovascular mortality and morbidity.

\section{INTRODUCTION}

Several studies have shown that changes in air temperature are associated with hospital admissions $^{1}{ }^{2}$ and mortality ${ }^{3-5}$ due to cardiovascular events. Elderly people and those with diabetes or chronic obstructive pulmonary disease (COPD) seem to be susceptible to extreme weather conditions. ${ }^{6-8}$ However, the underlying mechanisms of the relationship between temperature and cardiovascular morbidity remain poorly understood.

Earlier studies on the controlled exposure of participants to cold air or water revealed an increase

\section{What this paper adds}

- Air temperature changes have been associated with increased cardiovascular and respiratory risk for mortality and morbidity, but the roles of inflammatory and coagulation markers and adhesion molecules in these relationships are not well understood.

- We observed significant changes in adhesion molecules and in inflammatory and coagulation blood markers.

- We found some conflicting associations in patients with coronary heart disease and pulmonary disease.

- The complex interplay of blood markers at low temperature may contribute to the observed association between temperature decrease and cardiovascular mortality and morbidity.

- Susceptible subgroups should take preventive/ precautionary measures when the temperature drops.

in the levels of red blood cells (RBC), platelets, factor VII (FVII) and fibrinogen and a decline in von Willebrand factor (vWf). ${ }^{9-11}$ A Taiwanese study ${ }^{12}$ found higher mean fibrinogen and FVII concentrations on days with an ambient temperature equal to or below $20^{\circ} \mathrm{C}$ compared to days with an ambient temperature above $20^{\circ} \mathrm{C}$. Seasonal variations in C-reactive protein (CRP) levels were observed in healthy Koreans with higher values during winter and spring than in summer. ${ }^{13}$ The association between temperature and repeated fibrinogen, CRP and interleukin-6 (IL-6) measurements was assessed in a multi-centre European study of survivors of myocardial infarction. ${ }^{14} \mathrm{~A}$ decrease in temperature 3 days before the measurement was associated with an increase in fibrin ogen, CRP and IL-6 levels seemed to be related to average temperature changes in the previous 5 days.

It is hypothesised that a wide range of blood markers are involved in the development of atherosclerosis leading to chronic as well as acute cardiovascular disease. In patients with coronary or pulmonary disease, increased levels of inflammatory or coagulation markers might predict future cardiovascular events. ${ }^{15}{ }^{16}$ Therefore, 
elevated blood markers due to decreased temperature might indicate cardiovascular health. The objective of our study was to assess the influence of temperature on repeated measurements of cellular blood components, adhesion molecules and coagulation as well as inflammatory markers as indicators for cardiovascular health in susceptible subgroups. We investigated the direction and temporal delay of the temperature-blood marker response and whether this differs in subjects with pulmonary and cardiovascular disease. Our hypothesis was that there would be a similar response to temperature stimuli in both groups. Abnormalities in the haemostatic system and low-grade systemic inflammation were found in people with diabetes. ${ }^{17} 18$ Nakaji et a ${ }^{19}$ observed an increase in diabetes-related mortality during the winter season in Japan; thus, we were also interested in the possible effect modifications of diabetes status on the relationship between temperature and blood markers.

\section{METHODS \\ Study populations}

As part of the University of Rochester Particulate Matter Center investigations, two prospective panel studies were conducted in Erfurt, Germany. The first study was carried out between 15 October 2000 and 27 April 2001 with a group consisting of non-smoking men with coronary heart disease (CHD). Male participants with a history of doctor-diagnosed impaired lung function and/or chronic pulmonary disease took part in the second study between 15 October 2001 and 6 May 2002. All participants signed a written consent form and the study protocol was approved by the Ethics Commission of the Bavarian Chamber of Physicians ('Bayerische Landesaerztekammer'). Patients taking anti-coagulants (except for acetylsalicylic acid) and those with an implanted cardiac pacemaker, a recent $(<3$ months previously) myocardial infarction, bypass surgery, coronary angioplasty or diabetes mellitus type I were excluded from both groups. Additionally, participants in the pulmonary disease (PD) group with pneumoconiosis (silicosis or asbestosis), more than three hospitalisations for COPD in the previous year, or continuing oxygen therapy and those who had taken antibiotics more than four times during preceding 6 months or winter half-year were excluded.

\section{Clinical measurements}

For each participant up to 12 clinical examinations were scheduled every two weeks on the same week day and at the same time of day. At the first visit, a baseline questionnaire was administered regarding health status, pulmonary and cardiac symptoms, medication and smoking history. Each visit included a short interview and ethylenediaminetetraacetic acid (EDTA) and citrate plasma samples were drawn (Becton Dickinson, Franklin Lakes, NJ). Samples were centrifuged and aliquots were immediately stored at $-20^{\circ} \mathrm{C}$ until analysis. All blood specimens were analysed using an Abbott Cell-Dyn 1800 cell counter (Abbott, Wiesbaden, Germany). Intercellular adhesion molecule 1 (ICAM-1), endothelial-leukocyte adhesion molecule (Eselectin) (R\&D Systems, Wiesbaden, Germany), prothrombin fragment $1+2$ (Dade Behring, Marburg, Germany) and soluble CD40 ligand (sCD40L) were measured by means of a commercial enzyme-linked immunosorbent assay (ELISA). sCD40L measurements were only available for the CHD group. D-dimer and vWf were analysed using an immunoturbidimetric method and FVII by clotting time (Diagnostica Stago, Asnieres-sur-Seine, France). Fibrinogen, CRP (high-sensitivity assay) and serum amyloid A (SAA) were analysed by immunonephelometry (Dade Behring).

\section{Meteorological data}

Hourly data on temperature, relative humidity and barometric pressure were collected from existing networks. For each person and visit, the individual $24 \mathrm{~h}$ average of each meteorological variable preceding the visit ( $0-23 \mathrm{~h}$ before blood withdrawal) for up to 4 days ( $24-47 \mathrm{~h}, 48-71 \mathrm{~h}, 72-95 \mathrm{~h}, 96-119 \mathrm{~h}$ ) before the examination were calculated if more than two thirds of the hourly measurements were available for this period. Additionally, we calculated the mean of these 5 days (5-day average).

\section{Statistical analysis}

Analyses were performed with SAS (v 9.1) in both groups separately. The medians of patient-specific correlation coefficients between all blood markers were calculated. In order to compare the blood parameters between the groups, the two datasets were combined and mixed models with random patient effects were conducted including a dummy variable for the group effect. We assumed a compound symmetry structure for the covariance matrix, as the half-lives of the markers were much shorter than the intervals between the visits. To compare the meteorological variables between the groups, a regression model with a first-order autoregressive covariance structure was used to account for the dependencies between the repeated measurements. The $p$ value of the group effect indicates whether the blood markers and meteorological variables differ significantly between the groups. The patient characteristics of both groups were compared using a t test for metric variables and a $\chi^{2}$ test for categorical variables. In case of less than five observations in one category, Fisher's exact test was used.

Regarding the estimation of temperature effects, the data of each group were analysed separately using additive mixed models with random patient effects and a compound symmetry covariance structure. In both groups, prothrombin fragment 1 +2 , CRP, SAA and D-dimer and, only in the CHD group, sCD40L and FVII were log-transformed in order to produce normally distributed residuals. Penalised splines (P-splines) were used to allow for non-linear exposure-response functions and for non-linear confounder adjustment (S Greven, H Küchenhoff, A Peters, personal communication, 2008).

Confounder models were built separately for each blood parameter. Model selection was carried out by minimising Akaike's information criterion. Continuous confounders were included linearly or smoothly as P-splines depending on the Akaike's information criterion value. Long-term time trend and relative humidity with the same lag as the temperature term were forced into the model. Barometric pressure with the same lag as the analysed temperature lag and day of the week were only included in case of model fit improvement. Two variables with questionnaire information indicating an airway infection or antibiotic intake 2 weeks before blood withdrawal were forced into the model to account for possible inflammation unrelated to a change in temperature. In addition, for the PD group, a variable for corticosteroid intake was also taken into account. Observations with obviously large residuals in the confounder model were excluded.

After completion of the confounder models, the effects of temperature lags were estimated linearly as well as smoothly as P-splines. The linearly estimated temperature effects are presented as per cent change in the outcome mean per $10^{\circ} \mathrm{C}$ decrease in temperature together with $95 \%$ CIs. We chose to 
present the effects of a decrease in temperature because both groups were mainly studied in the winter.

\section{Effect modification}

We considered body mass index (BMI) $\left(\leq 30 \mathrm{~kg} / \mathrm{m}^{2}\right.$ vs $>30 \mathrm{~kg} /$ $\mathrm{m}^{2}$ ), hypertension (yes vs no), age ( $\leq 60$ years vs $>60$ years) and statins (intake vs no intake) as potential effect modifiers. The interaction with diabetes type II (yes vs no) was only analysed for the CHD group as only two patients in the PD group had diabetes. Additionally, interactions with smoking status (current smokers vs non-smokers) and $\beta 2$-agonists (intake vs no intake) were analysed for PD patients.

\section{Sensitivity analyses}

To check the robustness of our models we performed several sensitivity analyses. Temperature effects were calculated including observations with extremes in the residuals to avoid exclusion of observations possibly sensitive to temperature changes and to test the sensitivity of the results to our main model. Also, patients with pulmonary disease (COPD, chronic bronchitis) were excluded from the CHD group, and patients with coronary disease $(\mathrm{CHD}$, angina pectoris and previous myocardial infarction) from the PD group. Additionally, we separately added particulate matter with a diameter below $10 \mu \mathrm{m}\left(\mathrm{PM}_{10}\right)$ or ultrafine particles (UFP) with the same lag as temperature, as well as with the most influential lag, to the original confounder model. Polynomial distributed lag (PDL) models were calculated, which include all temperature lags simultaneously. In order to avoid multicollinearity, we used an Almon distributed lag model, ${ }^{20}$ which forces estimates to a polynomial shape. The sum of the lagged temperature effects resulting from a PDL model were compared with the effect of the 5-day temperature average.

\section{RESULTS}

\section{Study populations}

Of the initial $61 \mathrm{CHD}$ patients, one refused to participate, two were excluded due to disease causing changes in blood markers (leukaemia, lymphoma) and one was excluded because of constantly elevated levels of leukocytes and erythrocytes, indicating an unknown underlying disease. The CHD group therefore comprised 57 men. Fifty five patients participated in 12 scheduled visits, while two attended nine and eight examinations, respectively. If patients reported an acute infection and/or surgery during the 2 weeks before the examination or if nurses saw signs of acute infection, the blood samples of the respective visits were excluded (46 blood samples from 19 patients). As not all patients were able to give the scheduled amount of blood at each visit, 578 (85\%) blood samples remained for analysis.

The data of 38 of 42 male PD participants were used for analyses: three participants with a single measurement and one patient with a cancer diagnosis were excluded. In total, 438 (96\%) of the targeted 456 visits were carried out. Blood withdrawal failed for technical reasons on 10 occasions and 47 blood samples were excluded because of fever the week before withdrawal or a diagnosed airway infection on the day of the visit. Thus, 381 (87\% of 438 blood withdrawals) valid blood samples were available for analysis. The majority of patients had chronic bronchitis and/or asthma with normal pulmonary function tests measured as forced expiratory volume in $1 \mathrm{~s}\left(\mathrm{FEV}_{1}\right) /$ forced vital capacity ratios above $70 \%$. Two patients had mild, seven moderate $\left(50 \% \leq \mathrm{FEV}_{1} / \mathrm{FEV}_{1 \text { predicted }}<80 \%\right)$ and five severe $(30 \% \leq$ $\left.\mathrm{FEV}_{1} / \mathrm{FEV}_{1 \text { predicted }}<50 \%\right)$ COPD.
The $\mathrm{PD}$ and $\mathrm{CHD}$ groups are described in table 1. CHD patients were significantly older than $\mathrm{PD}$ patients: the age of $\mathrm{CHD}$ and $\mathrm{PD}$ patients ranged from 51 to 76 years and from 35 and 78 years, respectively. Significantly more patients with chronic bronchitis were observed among CHD patients with diabetes than without diabetes. Overall, the PD group was healthier as the participants tended to be less obese and it included only two patients with diabetes, while the CHD group included 13 patients with diabetes.

\section{Clinical measurements}

Levels of blood parameters are summarised in table 2. Except for E-selectin, vWf, D-dimer and SAA, PD patients tended to have higher values than $\mathrm{CHD}$ patients. Only platelets, prothrombin fragment $1+2$ and ICAM-1 showed significant differences between the groups. CHD patients with diabetes had higher Eselectin and ICAM-1 levels compared to CHD patients without diabetes. CRP and SAA showed a moderate correlation of $r=0.7$ $(\mathrm{CHD})$ and $\mathrm{r}=0.6(\mathrm{PD})$ in both groups. None of the remaining blood markers were strongly correlated $(|r|<0.4)$ in either group.

\section{Meteorological data}

Meteorological data were measured on 198 and 204 days for the CHD and PD groups, respectively (see online supplemental table 1). The mean temperature during both study periods was $4^{\circ} \mathrm{C}(\mathrm{SD}$ $5^{\circ} \mathrm{C}$ ). Mean relative humidity was $84 \%$ (SD $9 \%$ ) and $83 \%$ (SD $12 \%$ ) and mean barometric pressure was $973 \mathrm{hPa}(\mathrm{SD} 10 \mathrm{hPa})$ and $980 \mathrm{hPa}(\mathrm{SD} 11 \mathrm{hPa}$ ) for the $\mathrm{CHD}$ and $\mathrm{PD}$ groups, respectively. Only barometric pressure showed a significant difference between the groups. The meteorological variables exhibited only low correlation $(|r| \leq 0.3)$. Online figure 1 compares the time series of temperature in both groups.

\section{Effects of air temperature}

There was no evidence in either group for a deviation in the linearity of the relationship between temperature and blood markers (data not shown). Figures 1 and 2 show the immediate, lagged and cumulative effects of a $10^{\circ} \mathrm{C}$ decrease in temperature. All figures are presented with the same scaling except for $\mathrm{RBC}$ which exhibits very small temperature effects. The association between temperature and RBC was quite similar for both groups, but with an immediate significant effect in $\mathrm{CHD}$ patients $(0.7 \%, 0.0 \%$ to $1.4 \%)$. In contrast, $\mathrm{CHD}$ patients reacted to a drop in temperature, particularly the 5-day average, with decreased $(-3.6 \%,-6.9$ to $-0.4 \%)$ platelet levels, whereas PD patients responded with increased (3.0\%, $0.6 \%$ to $5.5 \%)$ platelet levels. A decline in temperature was associated with an increase in $\mathrm{SCD} 40 \mathrm{~L}$ in $\mathrm{CHD}$ patients, with the 5-day temperature average showing the largest effect (18.5\%, $5.1 \%$ to $33.5 \%)$. Only in PD patients was a decline in all temperature lags associated with increased E-selectin levels. A drop in temperature for the 5-day average led to a $4.6 \%(0.2 \%$ to $9.1 \%)$ increase in ICAM-1 in CHD patients. A $-6.5 \%(-12.7 \%$ to $-0.2 \%)$ reduction in $\mathrm{vWf}$ 24-47 h before blood withdrawal was detected in PD patients. We observed large differences between the groups for the relationship between temperature and FVII. While PD patients showed an immediate decrease in FVII $(-5.6 \%,-10.4$ to $-0.7 \%)$, CHD patients exhibited an inverse association of roughly the same size with a delay of 2 days $(4.9 \%, 0.7 \%$ to $9.2 \%$ ). We found only in PD patients an association between temperature and prothrombin fragment $1+2$ with a delay of $1-3$ days with the largest effect for the 5 -day average $(25.9 \%$, $7.6 \%$ to $47.3 \%$ ). No clear effects were detected for fibrinogen. A 
Table 1 Baseline characteristics of the PD and CHD groups

\begin{tabular}{|c|c|c|c|c|c|c|}
\hline & \multicolumn{4}{|c|}{ CHD group $(n=57)$} & \multicolumn{2}{|l|}{ PD group $(n=38)$} \\
\hline & $\begin{array}{l}\text { All mean (SD) } \\
\text { or } n(\%)\end{array}$ & $\begin{array}{l}\text { No diabetes } \\
\text { mean (SD) or } n(\%)\end{array}$ & Diabetes, N (\%) & $\begin{array}{l}\text { p Value (no diabetes } \\
\text { vs diabetes) }\end{array}$ & mean (SD) or $\mathbf{n}(\%)$ & $\begin{array}{l}\text { p Value } \\
\text { (PD vs CHD) }\end{array}$ \\
\hline Age (years), mean (SD) & $66.3(6.0)$ & $66.0(6.2)$ & $67.3(5.7)$ & $0.50^{*}$ & $53.8(12.3)$ & $<0.001^{*}$ \\
\hline \multicolumn{7}{|l|}{ Age (years) } \\
\hline$\leq 60$ & $8(14)$ & $7(16)$ & $1(8)$ & $0.67 \neq$ & $17(45)$ & $<0.001 \dagger$ \\
\hline$>60$ & $49(86)$ & $37(84)$ & $12(92)$ & & $21(55)$ & \\
\hline$\leq 30$ & $42(74)$ & $31(70)$ & $11(85)$ & $0.48 \neq$ & $33(87)$ & $0.12 \dagger$ \\
\hline$>30$ & $15(26)$ & $13(30)$ & $2(15)$ & & $5(13)$ & \\
\hline \multicolumn{7}{|l|}{ Smoking } \\
\hline Never smoker & $15(26)$ & $14(32)$ & $1(8)$ & $0.15 \neq$ & $8(21)$ & $0.003 \ddagger$ \\
\hline Ex-smoker & $42(74)$ & $30(68)$ & $12(92)$ & & $23(61)$ & \\
\hline Current smoker & $0(0)$ & $0(0)$ & $0(0)$ & & $7(18)$ & \\
\hline Myocardial infarction & $43(57)$ & $33(75)$ & $10(77)$ & $0.89 \dagger$ & $8(21)$ & $<0.001 \dagger$ \\
\hline $\begin{array}{l}\text { Bypass surgery/balloon } \\
\text { dilatation }\end{array}$ & $49(68)$ & $37(84)$ & $12(92)$ & $0.67 \ddagger$ & $4(11)$ & $<0.001 \neq$ \\
\hline COPD§ (mild to severe) & $5(9)$ & $5(11)$ & $0(0)$ & $0.58 \neq$ & $14(37)$ & $<0.001 \dagger$ \\
\hline Chronic bronchitis & $2(4)$ & $0(0)$ & $2(15)$ & $0.05 \neq$ & $29(76)$ & $<0.001 \neq$ \\
\hline Emphysema & $0(0)$ & $0(0)$ & $0(0)$ & - & $5(13)$ & $0.009+†$ \\
\hline Bronchial asthma & $0(0)$ & $0(0)$ & $0(0)$ & - & $20(53)$ & $<0.001 \dagger \dagger$ \\
\hline Hypertension & $40(70)$ & $32(73)$ & $8(62)$ & $0.44 \dagger$ & $14(37)$ & $0.001 \dagger$ \\
\hline Diabetes & $13(23)$ & $0(0)$ & $13(100)$ & - & $2(5)$ & $0.02 \ddagger$ \\
\hline \multicolumn{7}{|l|}{ Medication use } \\
\hline Acetylsalicylic acid & $53(93)$ & $42(96)$ & $11(85)$ & $0.22 \neq$ & $11(29)$ & $<0.001 \neq$ \\
\hline
\end{tabular}

decrease in temperature $96-119 \mathrm{~h}$ before blood withdrawal and in the 5-day average led to a borderline significant reduction of about $5 \%$ in $\mathrm{CHD}$ patients, whereas $\mathrm{PD}$ patients showed elevated fibrinogen levels for a temperature decrease $24-47 \mathrm{~h}$ $(5.0 \%, 1.2 \%$ to $8.7 \%), 48-71 \mathrm{~h}(5.2 \%, 2.0 \%$ to $8.4 \%)$ and $72-95 \mathrm{~h}(3.4 \%, 0.5 \%$ to $6.4 \%)$ before blood withdrawal and for the 5 -day temperature average $(5.5 \%, 1.3 \%$ to $9.7 \%)$. We detected only in CHD patients influential associations between a temperature decrease and CRP. Nearly all temperature lags showed a statistically significant or borderline decrease in CRP, with the largest influence for the 5-day temperature average $(-16.1 \%,-26.8 \%$ to $-3.8 \%)$. In both groups we found no influence of temperature on WBC, D-dimer or SAA (data not shown).

\section{Effect modification}

Only CHD patients with diabetes exhibited a decrease in platelets in association with a decline in temperature (figure 3). Participants with and without diabetes showed elevated and decreased levels of E-selectin and vWf, respectively, due to a decrease in temperature, which were not significant. We observed the largest interaction effects between temperature and diabetes on FVII. Patients with diabetes showed strongly elevated FVII values for a decrease in temperature for almost all lags, while there were no effects for patients without diabetes. No significant interactions by diabetes were detected in association with the remaining blood markers.

Temperature effects on platelets were more pronounced in CHD patients without statin intake, whereas CHD patients taking statins showed larger effects on E-selectin (data not shown). In PD patients we observed only temperature effects on prothrombin fragment $1+2$ in patients with statin intake. Throughout all $24 \mathrm{~h}$ lags, these participants exhibited significantly elevated levels due to a drop in temperature, whereas the effect of patients who did not take statins was smaller and mostly not significant. In both groups, no significant interactions of temperature with age, BMI or hypertension were detected. Smoking status and intake of $\beta 2$-agonists did not modify the temperature-blood marker response in $\mathrm{PD}$ patients.

\section{Sensitivity analyses}

In both groups the temperature effects remained robust after adjustment for air pollution. Only in CHD patients were temperature effects on RBC, ICAM-1 and vWf more pronounced after adjusting for $\mathrm{PM}_{10}$ with the same lag as temperature. The exclusion of PD patients from the CHD group and of patients with coronary disease from the PD group did not change our 
Table 2 Blood marker levels for PD and CHD patients

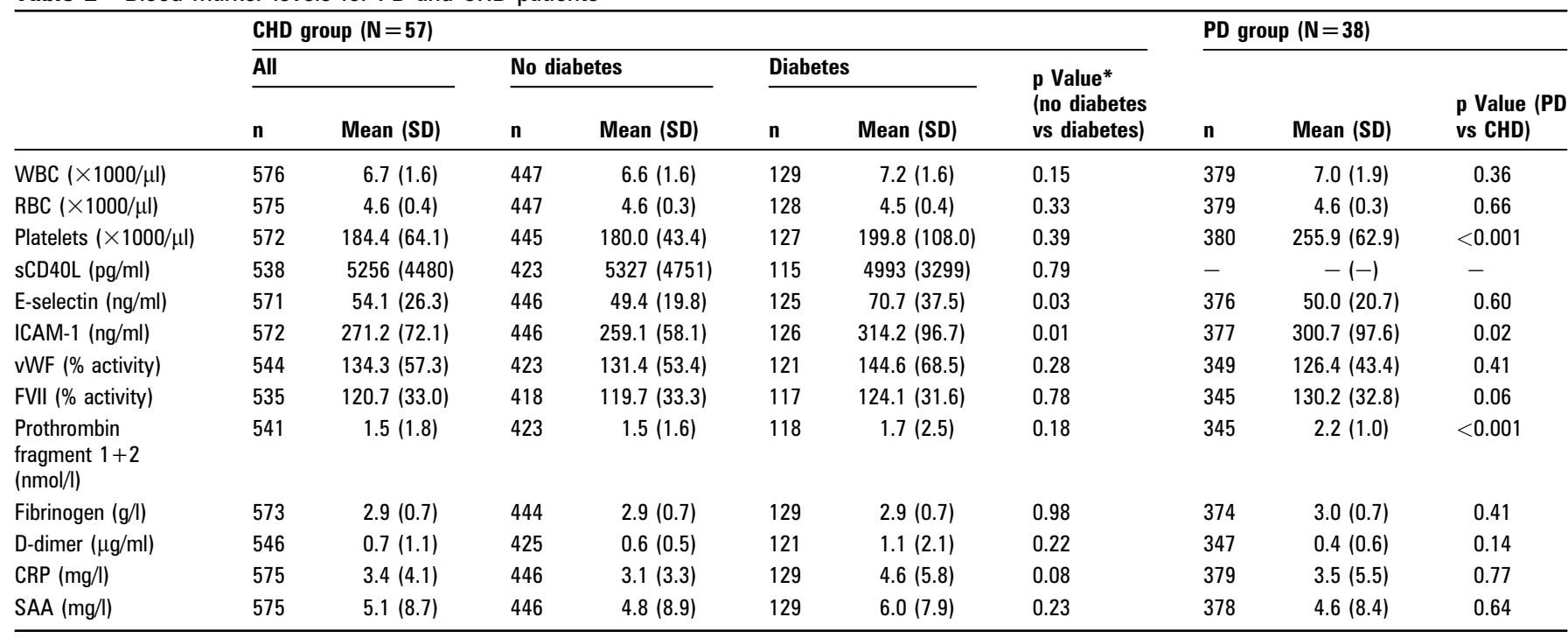

${ }^{*} \mathrm{p}$ Value of fixed group effect in mixed effects model.

CHD, coronary heart disease; CRP, C-reactive protein; E-selectin, endothelial-leukocyte adhesion molecule; FVII, factor VII; ICAM-1, intercellular adhesion molecule 1; PD, pulmonary disease; $\mathrm{RBC}$, red blood cell count; SAA, serum amyloid A; sCD40L, soluble CD40 ligand; vWF, von Willebrand-factor antigen; WBC, white blood cell count.

findings. The sums of the lagged temperature effects resulting from PDL analyses were comparable to the effects of 5-day temperature average on all blood markers in both groups (data not shown).

\section{DISCUSSION}

\section{Summary}

We investigated the cardiovascular effects of temperature in two susceptible subgroups. We observed opposite air temperature effects between the groups for platelets, E-selectin, prothrombin fragment $1+2$, FVII and fibrinogen. In association with a $10^{\circ} \mathrm{C}$ decline in temperature, PD patients showed an increase in blood parameters except for FVII, while CHD patients showed constant or decreased blood marker levels. Inverse immediate and lagged effects were found on SCD40L, which was measured in the CHD group only. Immediate decreased FVII levels in association with a $10^{\circ} \mathrm{C}$ decrease in the $24 \mathrm{~h}$ temperature average were detected in PD participants, whereas CHD patients showed increased FVII levels with a delay of 48-71 h. Patients with CHD and diabetes showed in particular a strong association between temperature and platelets as well as FVII, whereas no or opposite effects were observed in both $\mathrm{PD}$ and $\mathrm{CHD}$ participants without diabetes, respectively. The results indicate that decreases in temperature might lead to changes in coagulation markers and adhesion molecules, suggesting a biological mechanism for the observed temperature-related variation in cardiovascular event frequency.

\section{Air temperature and blood parameters}

$\mathrm{RBC}$ tended to increase as temperature decreased. These findings support other studies which showed elevated RBC after cooling. ${ }^{911}$ Elwood et $a l^{21}$ found an absolute increase in platelets of $16 \times 10^{3} / \mu \mathrm{l}$ in association with a $16^{\circ} \mathrm{C}$ decrease in temperature which is comparable with the $10 \times 10^{3} / \mu$ l platelet increase in PD patients for the same temperature decline found in our analysis. Increased platelet counts were also observed during mild surface cooling, ${ }^{11}$ probably as a consequence of cold-induced sympathetic activity. Contrary to our findings in PD participants, we observed a positive association in CHD patients. Considering the significantly increased sCD40L levels in CHD participants, the decrease in platelets could be the consequence of platelet aggregation due to activation of platelets. ${ }^{22}$ Unfortunately, no sCD40L data were available for the PD group to allow us further investigate this hypothesis. De Lorenzo et a ${ }^{10}$ showed that vWf, a glycoprotein which mediates platelet adhesion, decreased in healthy participants due to cold adaptation following whole body water immersion. In our results, reduced vWf levels in association with a drop in temperature were seen in both groups. However, the effects were mostly not significant.

FVII activates the clotting cascade and Woodhouse et al l $^{23}$ observed enhanced FVII clotting activity values in the elderly during winter. However, one should only cautiously refer to studies comparing winter-time and summer-time levels of blood markers, as the differences may be due to differences in influenza occurrence rather than temperature changes. Yeh et al ${ }^{12}$ found higher mean FVII levels in Taiwanese subjects on days with a temperature equal to or below $20^{\circ} \mathrm{C}$ in comparison to days exceeding $20^{\circ} \mathrm{C}$. Although temperature ranges between our and the Taiwanese study differed, we also detected cold effects on FVII in CHD patients. Opposite effects were observed in PD participants. Several studies 212324 observed enhanced fibrinogen levels in the elderly during winter. To our knowledge there was only one study which assessed the influence of temperature on repeated measurements of fibrinogen. Schneider et al ${ }^{14}$ observed increased fibrinogen levels in association with a decrease in temperature in survivors of myocardial infarction. A $10^{\circ} \mathrm{C}$ drop in temperature $72-95 \mathrm{~h}$ before blood withdrawal led to a $1.32 \%$ $(0.2 \%$ to $2.4 \%)$ increase in fibrinogen. We also found lagged temperature effects in $\mathrm{PD}$ patients, but our effects were larger and significant for several lags. However, in $\mathrm{CHD}$ patients a delayed decrease in fibrinogen was found. This is in accordance with the report by Frohlich et $a^{25}$ who reported peak fibrinogen levels in April and lower levels in winter. Fibrinogen is a precursor of fibrin which is responsible for thrombus formation. High levels of fibrinogen are a marker of systemic inflammation, while low levels can indicate systemic activation of the clotting cascade. Schneider et al ${ }^{14}$ detected elevated values of CRP in relation to a decline in temperature. However, we found no effect on CRP in PD patients and a decrease in CRP for almost all lags in $\mathrm{CHD}$ patients. The findings on seasonal changes of CRP are controversial. While Sung ${ }^{13}$ reported seasonal variation in CRP levels with a peak in winter, 

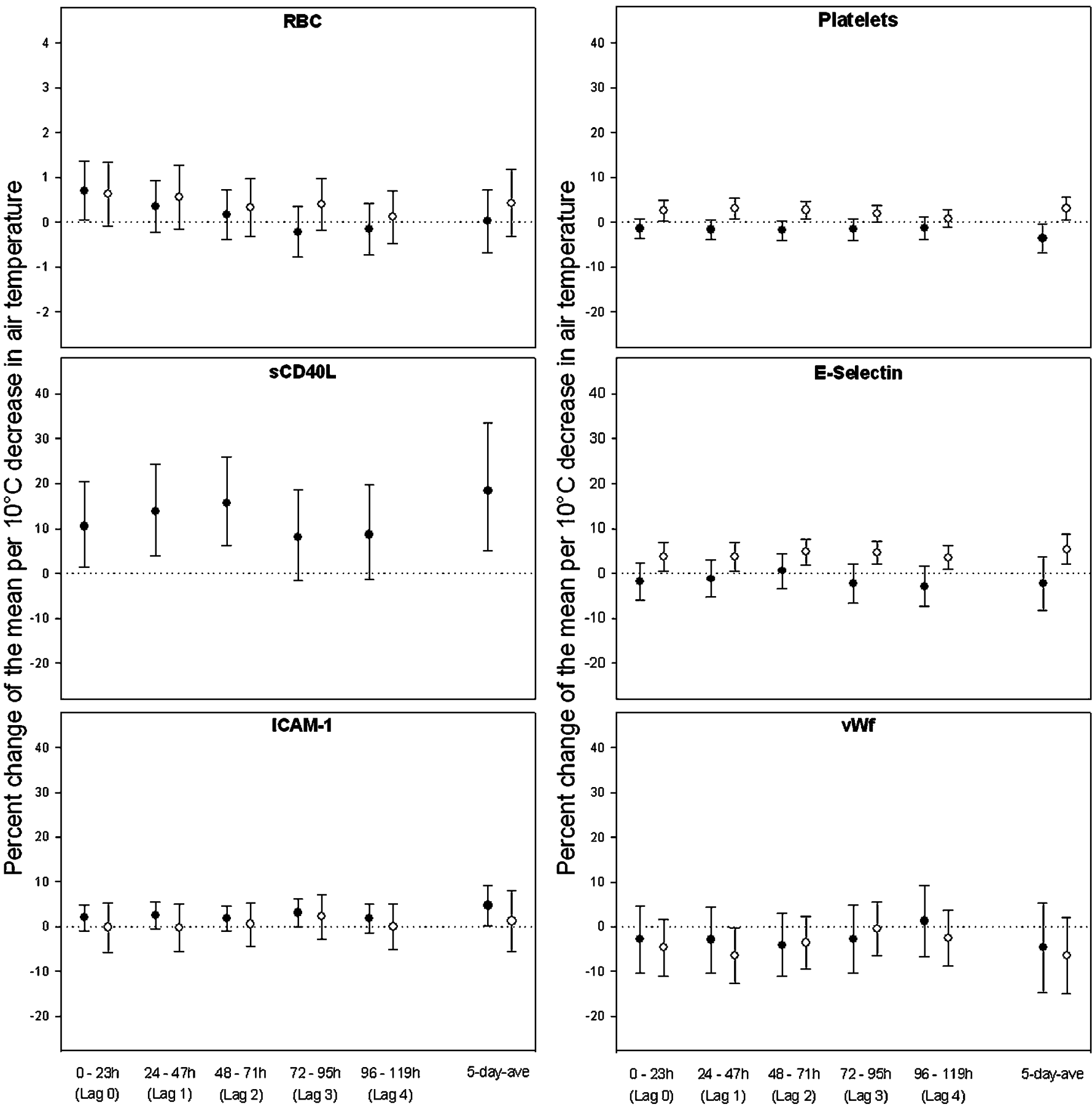

- $\mathrm{CHD} \quad$ OPD

Figure 1 Per cent change per $10^{\circ} \mathrm{C}$ decrease in temperature in mean levels of red blood cells (RBC), platelets, soluble CD40 ligand (sCD40L), E-selectin, intercellular adhesion molecule 1 (ICAM-1) and von Willebrand-factor antigen (vWF). CHD, coronary heart disease; PD, pulmonary disease.

Horan et $a^{26}$ and Frohlich et $a l^{27}$ found no seasonal variation. CRP is the most established inflammatory marker used to evaluate and predict cardiovascular health. ${ }^{15}$ However, we mainly observed changes in coagulation markers which might also be relevant in the development of acute coronary syndromes and in thrombus formation. ${ }^{28}$

Air temperature and blood parameters in patients with diabetes We detected interaction effects between diabetic status and temperature on platelets, E-selectin, vWf and FVII in CHD patients. The inverse influence of a drop in temperature on FVII in all CHD patients might be based on the strong inverse temperature effect in people with diabetes. CHD patients without diabetes showed non-significant effects comparable to the estimates for the PD group, which included only two patients with diabetes. While smaller or opposite effects were detected in patients without diabetes, a decline in temperature also led to decreased platelets and slightly increased E-selectin and vWf levels in patients with diabetes. The haemostatic system in individuals with diabetes exhibits various abnormalities ${ }^{17}$ such as endothelial 

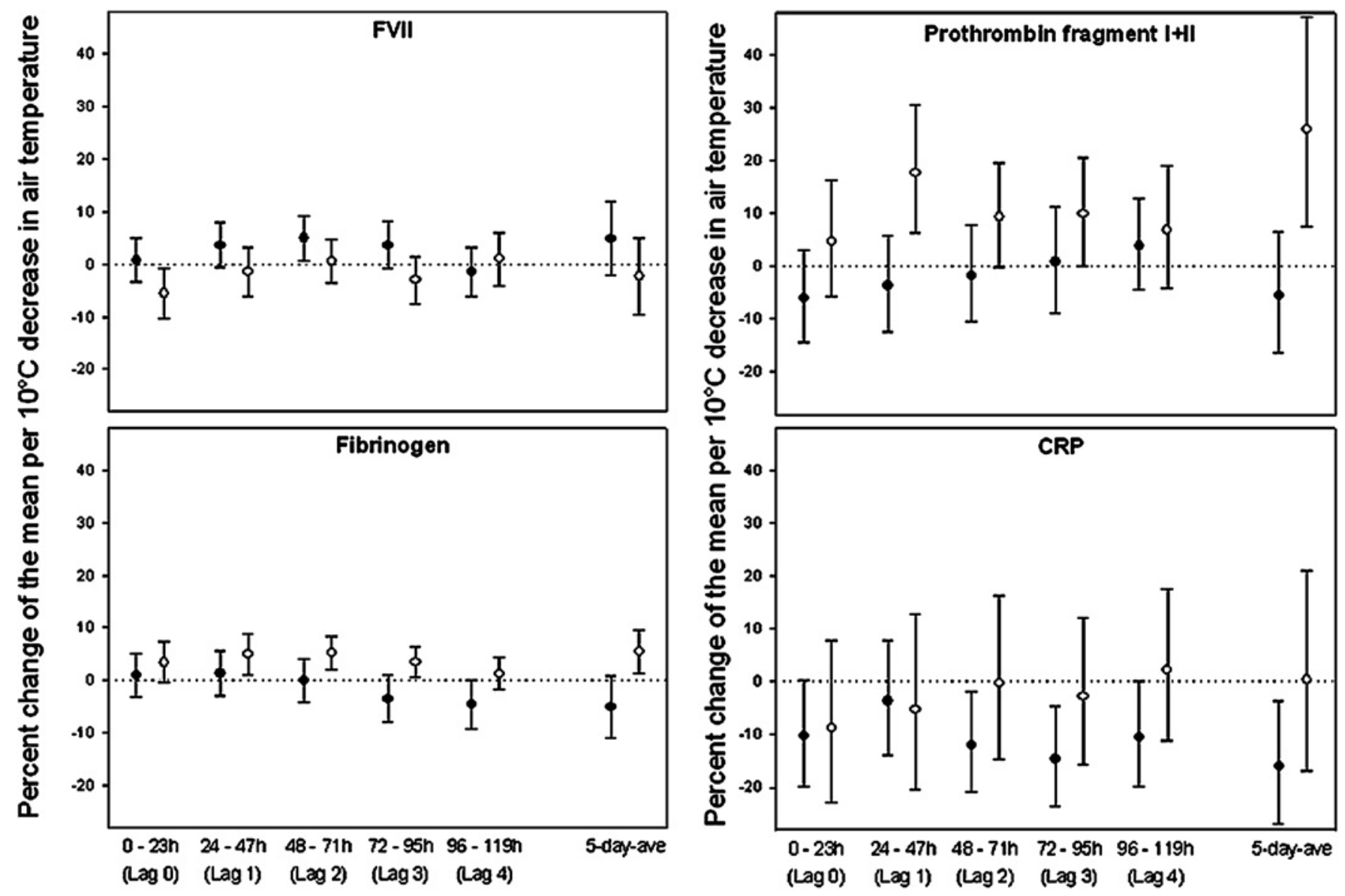

\section{- CHD $\quad$ PD}

Figure 2 Per cent change per $10^{\circ} \mathrm{C}$ decrease in temperature in mean levels of factor VII (FVII), prothrombin fragment $1+2$, fibrinogen and C-reactive protein (CRP). CHD, coronary heart disease; PD, pulmonary disease.

damage and elevated coagulation markers. The decrease in platelets in association with a temperature drop might be due to enhanced vWf levels which promote platelet adhesion to the damaged endothelial tissue and subsequent platelet activation. ${ }^{29}$ Our analyses revealed that patients with diabetes seem to be a susceptible subpopulation which reacted more strongly to cold temperature. This finding needs further investigation as Schwartz ${ }^{6}$ and Medina-Ramon and Schwartz ${ }^{30}$ observed in caseonly analyses increased hospital admissions and deaths in patients with diabetes on extremely hot days but no effects of extreme cold. As the study periods of our groups were limited to the cold season we expected no heat effects.

In summary, contrary to our initial hypothesis, the relationship between temperature and most blood markers differed between the groups or clear temperature effects were detected only in one group. CHD patients in our study were older and more often had hypertension and diabetes than PD patients. Medication also varied because of different disease patterns between the groups. The combination of all these factors possibly affected blood markers and susceptibility to temperature. Thus, differences in the effect of temperature between the groups could not be fully explained by a single patient characteristic. It is possible that underlying, but currently unknown, mechanisms influencing the association between temperature and blood markers might differ between the two susceptible subgroups. However, it is also possible that our results are only due to chance.

\section{Air temperature and cardiovascular events}

As several studies ${ }^{51}$ observed increases in cardiovascular events due to a decline in temperature, our analyses might identify intermediate steps linking temperature changes to cardiovascular health. The influence of temperature on cardiovascular events has also been described by U-, V- or J-shaped functions. ${ }^{2} 32-34$ In this context, it is important to note that the clinical examinations of the CHD and PD patients took place from October to April or May, respectively. The maximum $24 \mathrm{~h}$ averages in temperature during both study periods never exceeded $16^{\circ} \mathrm{C}$. We assume that our results reflect the left part of a U- or V-shaped temperature-blood marker response as it has been shown that cardiovascular mortality is lowest on days with a mean temperature between $15^{\circ} \mathrm{C}$ and $20^{\circ} \mathrm{C}^{34}$

\section{Strengths and limitations}

We were able to analyse intra-individual variation as patients with $\mathrm{PD}$ or $\mathrm{CHD}$ participated in up to 12 consecutive blood measurements. Further strengths are the non-linear confounder adjustment and the information on patient characteristics allowing us to perform subgroup analyses. However, the findings are limited in that the measured blood markers are easily influenced by infections. CRP is particularly sensitive to infectious disease and can increase a thousand-fold within a short time. ${ }^{35}$ We therefore excluded the blood samples of participants with an acute infection during their visit and we additionally 

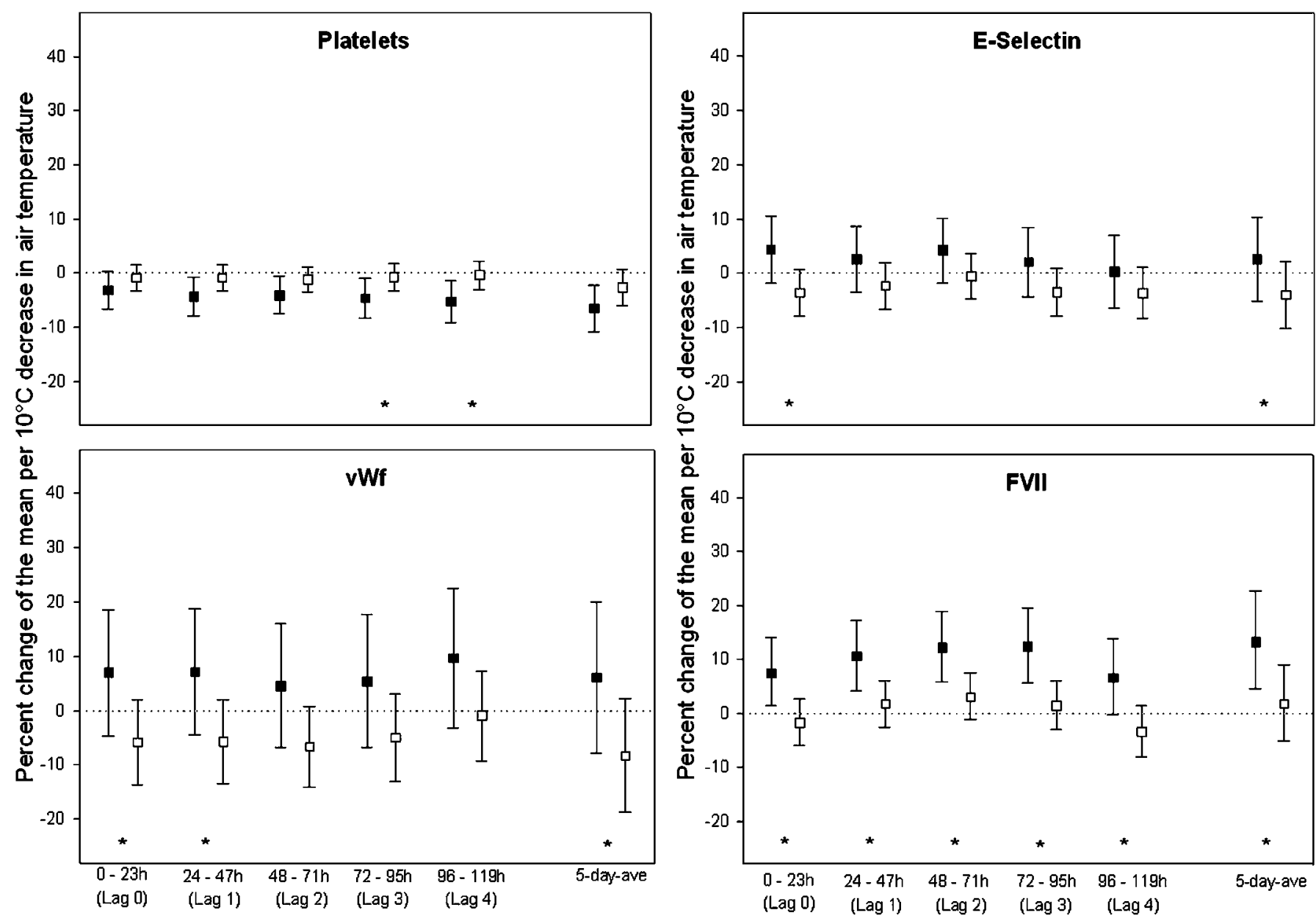

- Diabetes a No diabetes

Figure 3 Per cent change per $10^{\circ} \mathrm{C}$ decrease in temperature in mean levels of blood markers for coronary heart disease patients with and without diabetes. ${ }^{*}$ Interaction is significant.

adjusted for intake of antibiotics and airway infections during the 2 weeks prior to the examination. It can therefore be assumed that the presented effects result from a temperature decrease and not from an infectious disease. It has also been shown that air pollutants might be associated with blood markers. ${ }^{36-42}$ It is still unclear whether air pollutants confound or modify the temperature-blood marker response. However, adjustment for air pollution hardly changed our results.

There is no standard technique to determine sCD40L and it has been shown that sCD40L levels may be influenced by the method employed. However, in our study all samples were analysed at the same time and under the same conditions (for further details, see Rückerl et $a l^{22}$ ). Moreover, the change in the sCD40L level within one patient was used for analysis, rather than the absolute level, and therefore the assay itself cannot have influenced the results.

One limitation is that we investigated the influence of temperature on blood parameters in men with severe disease on different medication. Hence, they are a highly selected group which might show differing reactions to temperature changes compared to women or healthy subjects, leading to reduced generalisability of our results. On the other hand, analysing vulnerable groups might provide more mechanistic insights and provide ideas for instituting new precautions. A further limitation is that only outdoor temperature was measured although people usually spend a lot of time indoors, especially in winter. However, as numerous studies have shown that the risk for cardiovascular events increases during the cold season, 534 we assume that short exposure to outdoor temperature can also influence blood markers.

\section{CONCLUSION}

The present study suggests that a decrease in temperature is associated with changes in several blood parameters. The direction and timing of the relationship differed between $\mathrm{CHD}$ and $\mathrm{PD}$ patients. The complex interplay of blood markers at low temperature may contribute to the observed association between cold and cardiovascular mortality and morbidity.

\footnotetext{
Author affiliations

${ }^{1}$ Helmholtz Zentrum München, German Research Center for Environmental Health, Institute of Epidemiology, Neuherberg, Germany

${ }^{2}$ Department of Medicine-Pulmonary and Critical Care Division, University of Rochester School of Medicine and Dentistry, Rochester, New York, USA

${ }^{3}$ Department of Cardiology, University of Ulm, Ulm, Germany

${ }^{4}$ Department of Environmental Medicine-Lung Biology and Disease Program, University of Rochester School of Medicine and Dentistry, Rochester, New York, USA ${ }^{5}$ IBE Chair of Epidemiology, Ludwig-Maximilians-University of Munich, Munich, Germany
}

Funding This study received funding from the U.S. Environmental Protection Agency through STAR grants R 827354 and RD832415 to the University of Rochester. 


\section{Competing interests None.}

Ethics approval This study was conducted with the approval of the Ethics Commission of the Bavarian Chamber of Physicians ('Bayerische Landesaerztekammer').

Provenance and peer review Not commissioned; externally peer reviewed.

\section{REFERENCES}

1. Schwartz J, Samet JM, Patz JA. Hospital admissions for heart disease: the effects of temperature and humidity. Epidemiology 2004;15:755-61.

2. Liang WM, Liu WP, Chou SY, et al. Ambient temperature and emergency room admissions for acute coronary syndrome in Taiwan. Int J Biometeorol 2008;52:223-9.

3. Braga AL, Zanobetti A, Schwartz J. The effect of weather on respiratory and cardiovascular deaths in 12 U.S. cities. Environ Health Perspect 2002;110:859-63.

4. Wolf K, Schneider A, Breitner S, et al. Air temperature and the occurrence of myocardial infarction in Augsburg, Germany. Circulation 2009;120:735-42.

5. Analitis A, Katsouyanni K, Biggeri A, et al. Effects of cold weather on mortality: results from 15 European cities within the PHEWE project. Am J Epidemiol 2008:168:1397-408

6. Schwartz J. Who is sensitive to extremes of temperature?: a case-only analysis Epidemiology 2005;16:67-72.

7. Medina-Ramon M, Zanobetti A, Cavanagh DP, et al. Extreme temperatures and mortality: assessing effect modification by personal characteristics and specific cause of death in a multi-city case-only analysis. Environ Health Perspect 2006;114:1331-6.

8. Hajat S, Kovats RS, Lachowycz K. Heat-related and cold-related deaths in England and Wales: who is at risk? Occup Environ Med 2007:64:93-100.

9. Neild PJ, Syndercombe-Court D, Keatinge WR, et al. Cold-induced increases in erythrocyte count, plasma cholesterol and plasma fibrinogen of elderly people without a comparable rise in protein C or factor X. Clin Sci (Lond) 1994:86:43-8.

10. De Lorenzo F, Kadziola Z, Mukherjee $M$, et al. Haemodynamic responses and changes of haemostatic risk factors in cold-adapted humans. OJM 1999:92:509-13.

11. Keatinge WR, Coleshaw SR, Cotter F, et al. Increases in platelet and red cell counts, blood viscosity, and arterial pressure during mild surface cooling: factors in mortality from coronary and cerebral thrombosis in winter. Br Med J (Clin Res Ed) 1984;289:1405-8.

12. Yeh CJ, Chan P, Pan WH. Values of blood coagulating factors vary with ambient temperature: the Cardiovascular Disease Risk Factor Two-Township Study in Taiwan. Chin J Physiol 1996;39:111-16.

13. Sung KC. Seasonal variation of C-reactive protein in apparently healthy Koreans. Int J Cardiol 2006;107:338-42.

14. Schneider A, Panagiotakos D, Picciotto $S$, et al. Air temperature and inflammatory responses in myocardial infarction survivors. Epidemiology 2008;19:391-400.

15. Libby P, Ridker PM, Maseri A. Inflammation and atherosclerosis. Circulation 2002;105:1135-43.

16. Maclay JD, McAllister DA, Macnee W. Cardiovascular risk in chronic obstructive pulmonary disease. Respirology 2007;12:634-41.

17. Banga JD. Coagulation and fibrinolysis in diabetes. Semin Vasc Med 2002;2:75-86.

18. Duncan BB, Schmidt Ml. The epidemiology of low-grade chronic systemic inflammation and type 2 diabetes. Diabetes Technol Ther 2006;8:7-17.

19. Nakaji S, Parodi S, Fontana V, et al. Seasonal changes in mortality rates from main causes of death in Japan (1970-1999). Eur J Epidemiol 2004;19:905-913.

20. Almon S. The distributed lag between capital appropriations and expenditures. Econometrica 1965;33:178-96.

21. Elwood PC, Beswick A, O'Brien JR, et al. Temperature and risk factors for ischaemic heart disease in the Caerphilly prospective study. Br Heart J 1993;70:520-3.
22. Rückerl R, Phipps RP, Schneider A, et al. Ultrafine particles and platelet activation in patients with coronary heart disease-results from a prospective panel study. Part Fibre Toxicol 2007;4:1.

23. Woodhouse PR, Khaw KT, Plummer M, et al. Seasonal variations of plasma fibrinogen and factor VII activity in the elderly: winter infections and death from cardiovascular disease. Lancet 1994;343:435-9.

24. Kelly GS. Seasonal variations of selected cardiovascular risk factors. Altern Med Rev 2005; 10:307-20.

25. Frohlich M, Sund M, Russ $\mathrm{S}$, et al. Seasonal variations of rheological and hemostatic parameters and acute-phase reactants in young, healthy subjects. Arterioscler Thromb Vasc Biol 1997;17:2692-7.

26. Horan JT, Francis CW, Falsey AR, et al. Prothrombotic changes in hemostatic parameters and $\mathrm{C}$-reactive protein in the elderly with winter acute respiratory tract infections. Thromb Haemost 2001;85:245-9.

27. Frohlich $\mathbf{M}$, Sund $\mathbf{M}$, Thorand $\mathrm{B}$, et al. Lack of seasonal variation in $\mathbf{C}$-reactive protein. Clin Chem 2002;48:575-7.

28. Davi G, Patrono C. Platelet activation and atherothrombosis. N Engl J Med 2007;357:2482-94.

29. Grant PJ. Diabetes mellitus as a prothrombotic condition. J Intern Med 2007:262:157-72.

30. Medina-Ramon M, Schwartz J. Temperature, temperature extremes, and mortality: a study of acclimatization and effect modification in 50 United States cities. Occup Environ Med 2007;64:827-33.

31. Panagiotakos DB, Chrysohoou C, Pitsavos C, et al. Climatological variations in daily hospital admissions for acute coronary syndromes. Int J Cardiol 2004;94:229-33.

32. Sharovsky R, Cesar LA, Ramires JA. Temperature, air pollution, and mortality from myocardial infarction in Sao Paulo, Brazil. Braz J Med Biol Res 2004;37:1651-7.

33. Baccini M, Biggeri A, Accetta G, et al. Heat effects on mortality in 15 European cities. Epidemiology 2008;19:711-19.

34. Nayha S. Cold and the risk of cardiovascular diseases. A review. Int J Circumpolar Health 2002;61:373-80.

35. Thomas L. Labor und diagnose. Frankfurt a. Main, Germany: TH-Books Verlagsgesellschaft, 1998.

36. Rückerl R, Ibald-Mulli A, Koenig W, et al. Air pollution and markers of inflammation and coagulation in patients with coronary heart disease. Am J Respir Crit Care Med 2006;173:432-41.

37. Rückerl R, Greven $\mathrm{S}$, Ljungman $\mathrm{P}$, et al. Air pollution and inflammation (interleukin-6 C-reactive protein, fibrinogen) in myocardial infarction survivors. Environ Health Perspect 2007;115:1072-80.

38. Chuang KJ, Chan CC, Su TC, et al. The effect of urban air pollution on inflammation, oxidative stress, coagulation, and autonomic dysfunction in young adults. $\mathrm{Am} \mathrm{J}$ Respir Crit Care Med 2007;176:370-6.

39. Delfino RJ, Staimer N, Tjoa T, et al. Circulating biomarkers of inflammation, antioxidant activity, and platelet activation are associated with primary combustion aerosols in subjects with coronary artery disease. Environ Health Perspect 2008;116:898-906

40. Peters A, Frohlich M, Doring A, et al. Particulate air pollution is associated with an acute phase response in men; results from the MONICA-Augsburg Study. Eur Heart $J$ 2001;22:1198-204.

41. Pekkanen J, Brunner EJ, Anderson HR, et al. Daily concentrations of air pollution and plasma fibrinogen in London. Occup Environ Med 2000;57:818-22.

42. Brook RD, Franklin B, Cascio W, et al. Air pollution and cardiovascular disease: a statement for healthcare professionals from the Expert Panel on Population and Prevention Science of the American Heart Association. Circulation 2004; 109:2655-71 


\section{OEM}

\section{Air temperature and inflammatory and coagulation responses in men with coronary or pulmonary disease during the winter season}

Regina Hampel, Susanne Breitner, Regina Rückerl, et al.

Occup Environ Med 2010 67: 408-416 originally published online November 2, 2009

doi: 10.1136/oem.2009.048660

Updated information and services can be found at:

http://oem.bmj.com/content/67/6/408.full.html

These include:

References This article cites 41 articles, 13 of which can be accessed free at: http://oem.bmj.com/content/67/6/408.full.html\#ref-list-1

Article cited in:

http://oem.bmj.com/content/67/6/408.full.html\#related-urls

Email alerting Receive free email alerts when new articles cite this article. Sign up in service the box at the top right corner of the online article.

Notes

To request permissions go to:

http://group.bmj.com/group/rights-licensing/permissions

To order reprints go to:

http://journals.bmj.com/cgi/reprintform

To subscribe to BMJ go to:

http://group.bmj.com/subscribe/ 